\title{
Introduction
}

\section{Caught in the web: capturing the zeitgeist of 'Big Tech' companies, social media speech and privacy}

PAUL WRAGG*

University of Leeds

\begin{abstract}
The Circle, by Dave Eggers, ${ }^{1}$ is a dystopian novel in the classic tradition. Our young 1 protagonist, Mae, is an inexperienced and dreamy-eyed graduate who begins entry-level work at the eponymous Big Tech giant, The Circle, before progressing to the upper echelons. Through her eyes, we enter a world that seems perfect and virtuous ('My God, Mae thought. It's Heaven!'), but which hides, but only superficially, an authoritarian nightmare. For The Circle - a combination of all recognisable Big Tech companies - has become so embedded in society that it runs everything. Mae's job is initially as a customer experience technician, responsible for small advertisers. We quickly learn that perfect feedback is not an aspiration but an expectation. Mae's agony over a sub-100 per cent approval rating tells us something about the sinister environment she works in. She is not comforted by her score being a record for a new starter because she fears unspoken reprisals and negative reactions from her new colleagues. This speaks volumes about the modern service industry whilst also, at a deeper level, speaking to the split-personality that social media idealises: the individual who has both the unquenchable vanity for constant personal validation and the untameable desire to eviscerate others; in other words, the individual who is entirely sensitive, but lacks sensitivity entirely. As Mae becomes noticed by the company founders, through a series of misfortunes her dawning realisation about the true nature of The Circle leads her on a voyage of self-discovery, which terminates in selfrecrimination and personal tragedy.
\end{abstract}

Central to this narrative are The Circle's social and political ambitions to realise absolute transparency, in personal and professional life, ostensibly to improve society and the betterment of humankind. This project takes on cultish dimensions when consumers are encouraged (and employees expected) to wear cameras constantly, which broadcast in real time everything they do, every encounter they have, every interaction. This will, its creator believes, eradicate crime, stop corruption (particularly in public office) and improve understanding, as people relate to and learn from the experiences of others. But, for Mae, this has terrible consequences - as when her camera inadvertently captures her mother performing fellatio on her father - and causes her former boyfriend, a Luddite, to be chased to his death as he attempts to escape this brave new world. It is these extreme examples that reveal to the book's readers the profound effect that social media

* Associate Professor of Law; Associate Fellow, Inner Temple; Editor-in-Chief of Communications Law.

1 Penguin 2013. 
and Big Tech have upon our way of living. By normalising privacy-invasion and trivialising its effects, individuals are led to believe the slogans that The Circle utilises to its nefarious ends: 'Secrets are Lies', 'Sharing is Caring', 'Privacy is Theft'.

This pernicious challenge to social norms finds its equivalent in real life. Recently, Amber Rudd, as Home Secretary, said, with no sense of irony, "real people" aren't interested in security features that stop the government . . . reading their messages' ${ }^{2}$ The owners of Whatsapp were, therefore, morally reprehensible for failing to build 'backdoor' access to their product that would allow the government (but not anyone else) to view messages between users. In her view, only 'terrorists' and 'would-be terrorists' benefit from this impenetrable encryption. In other words, it is only them but not us who value privacy. This position echoes the US government's policy on intrusive surveillance: if you have nothing to hide, you have nothing to fear'. ${ }^{3}$ It speaks to an attitude that concern for privacy is sinister, shameful, or (somehow) unpatriotic. It also signals a misguided sense of trust amongst citizens that the intelligence service activities will only ever affect the lives of others, never them. Robert Post perceives this problem clearly when he warns of the 'extreme fragility of privacy norms in modern life': 'if [they are] not acknowledged and preserved, [privacy] will vanish'. ${ }^{4}$

This threat to privacy emanates from both private enterprise and government activity. It is well known that, for example, Google's advertising services are based partly on cookies (meta data capturing web-browsing activities). As will be recalled, Edward Snowden revealed much about both the US and UK's intelligence services. Specifically, the existence of three covert operations: PRISM, UPSTREAM and Tempora. In the UK, The Guardian wrote extensively about these programmes, which include Government Communications Headquarters (GCHQ) indiscriminately intercepting internet data traffic. ${ }^{5}$ It is alleged that GCHQ has intercepted the webcam images (much of which is of a sexual nature) of millions of ordinary people unsuspected of any wrongdoing. ${ }^{6}$ Currently, there is litigation pending in the European Court of Human Rights on this. ${ }^{7}$ It is alleged that the UK intelligence services accesses:

... electronic traffic passing along fibre-optic cables running between the UK and North America. The data collected include both internet and telephone communications ... the content of e-mails, Facebook entries and website histories. Data is accessed without the need for reasonable suspicion in relation to the activities of any particular targeted persons. ${ }^{8}$

Yet the popular response to this has been apathetic. As The Guardian (again) commented: 'The lack of public alarm at government internet surveillance is frightening, but perhaps

2 Andrew Griffin, "Real people” don't care if chat apps like Whatsapp keep their messages private if they get new features, says Amber Rudd' The Independent (London, 1 August 2017).

3 See discussion in Daniel J Solove, "Why privacy matters even if you have "nothing to hide" The Chronicle of Higher Education (15 May 2011).

4 Robert C Post, 'The social foundations of privacy: community and self in the common law tort' (1989) 77(2) California Law Review 957, 1010.

5 Nick Hopkins, 'UK gathering secret intelligence via covert NSA operation' The Guardian (London, 7 June 2013) <www.theguardian.com/technology/2013/jun/07/uk-gathering-secret-intelligence-nsa-prism>.

6 Spencer Ackerman and James Ball, 'Optic nerve: millions of Yahoo webcam images intercepted by GCHQ' The Guardian (London, 28 February 2014).

7 Big Brother Watch and Others $v$ UK, App No 58170/13 (ECHR, 8 November 2017) <www.privacynotprism.org.uk/assets/files/privacynotprism/496577_app_No_5817013_BBW_ORG_EP_CK_v_UK_Grounds.pdf $>$.

8 Ibid, Joint Application under Article 34, [31]. 
it's because the problem is difficult to convey in everyday terms.' ${ }^{\text {' }}$ It seems we have become desensitised to the harm that privacy-invasions cause or else conclude that this threat is a problem for others, never ourselves.

It is with these challenges in mind that a group of distinguished scholars gathered at the Inner Temple in May 2018 for a conference. This special issue contains the finished outputs from our discussions and reflections. The fake news phenomena and Cambridge Analytica scandal provide the context for Peter Coe's impressive paper. He argues, persuasively, that the expectations commentators place upon the traditional press, to act ethically and for the public good, should be extended to social media news outlets. This is especially pressing given the burgeoning influence of social media. As the US Presidential election and UK Brexit vote show, social media may be more powerful than traditional forms of media; certainly, the personal endorsement that 'likes' by friends, family and colleagues provide may be more influential than commentators have previously appreciated. Coe's argument is that the social responsibility theory popularised by the US Commission for Freedom of the Press, chaired by Robert Hutchins in 1947, provides a ready-made philosophical framework by which to judge the actions of social media news producers, and by which to formulate a model of governance.

On a similar theme, Laura Scaife rejects the common view that social media is unregulatable. In her view, the internet is comparable to the sea: just as regulation of the sea proved challenging but, ultimately, achievable, so too the internet can be regulated properly, but only if we alter our perspective of the means by which that regulation is to be achieved. So, it is that she argues for 'an iterative and dynamic model' of governance. Her broader point is that, also like the sea, although its scope is bewildering, the causes of harm raise issues intelligible to law.

... despite the changing times and tides, the nature of basic hazards associated with seafaring does not in essentials change, for example, collisions at sea, sinking, smuggling, environmental pollution and piracy. The full list of potential hazards at sea, much like social media (for example, copyright breaches, defamation, criminal speech, breach of privacy rights etc.) is extensive. My argument is that understanding the development of international maritime law can help prompt a dynamic, dialogue-based model for the regulation of international social media. (434)

Consequently, she envisages a fluid model of regulation which, rather than being fixed and inflexible, is responsive to changing social interactions and cultural needs for social media. In this way, she argues, meaningful regulation is achievable through constant dialogue between users and producers.

Robin Barnes takes this discussion in a different direction in her polemic piece, 'Weapons of mass distraction'. In her view, 'Nightly news delivered as propaganda leaves the core of the public's interest in an ill-defined space' (512) and a proliferation of 'journalism that advances insularity over public education concerning the demise of basic freedoms' (476). She makes many pertinent points as she surveys The Circle's real-world comparators, but her central theme is the pernicious use of social media 'news' to distract from serious newsworthy issues, to concentrate on the trivial and titillating. In this way, her article is a critical comment on the appetites of both US and UK audiences. Her concern is that the peculiar political climate, in which serious political debate is anathema in the land of the ethereal, threatens the culture of dissent that the US previously

9 John Naughton, 'Public apathy over GCHQ snooping is a recipe for disaster' The Guardian (London, 16 March 2014). 
embraced. For her, this is in marked contrast to the progress made following the civil rights movement which, although it had not reached its end in President Obama's reign, is now in serious jeopardy, for what is to be done about the normalisation - and, in some instances, downright idealisation - of rampant misogyny, Islamophobia and racial intolerance that the US and UK are now in the grip of?

Progressing with the theme of fake news and its discontents, Paul Bernal introduces a more positive note by reminding us that the phenomena is hardly new. In his fascinating contribution, we see its origins in the twelfth-century claims of Geoffrey of Monmouth that the kings of Britain were descended from King Arthur and, before that, the Trojan Aeneas. In this sense, there is an inevitably to the proliferation of 'fake news' to achieve social and political ends. It was ever thus. But, as he explains, the nature of Facebook and comparable social media platforms - creates a perfect storm for this behaviour to embed. First, convincing 'fake news' is simple to create. Modern technologies make it easy to replicate the appearance of authentic information. Secondly, the way that Facebook captures personal data makes it easy to get this information to people, and groups of people, who are likely to engage with it, believe it and disseminate it further. This sort of targeted marketing is much more effective in the digital era than it could ever have been previously. As Bernal says: 'Facebook does not just help with identifying the potential audience but also provides the mechanisms to target them - from the tools for advertisers to the various groups, pages and so forth where they can be found.' (521) A third problem relates to its mass appeal: 'Perhaps most importantly, fake news can be more believable than "real" news. It fits in with people's prejudices.' (ibid) This helps fake news purveyors to attain their goals. Despite the ease of identifying the problem, and the reasons for its success, the solution, assuming there is one, is problematic. As Bernal notes, tackling the source of fake news is no real solution because those sources will spring up interminably and unpredictably. Items could be flagged as 'fake news' but, as Donald Trump has shown so demonstrably, the label becomes a convenient, pernicious political tool to silence dissent. This insight causes Bernal to end on a pessimistic note: 'It is not possible to find a "clean" solution. Instead, messy, imperfect ways ahead may be the best way forward. This is not a problem that is going to go away any time soon.' (530)

The Circle also draws our attention to the special intrusiveness of pictures and images. Absolute transparency robs the individual of the autonomy to present herself to the world as she wants it to see her. It reveals the inner self: the anxieties, fears and flaws of both the physical self and mental state. It is this aspect of social media that Rebecca Moosavian examines in her thoughtful, skilful presentation of the law's response to these issues. Her rich analysis begins by noting the distinction that judges make between photographic and textual intrusions into private life; that the former is considered more intrusive than the latter. By engaging with the work of cultural theorists John Berger, Susan Sontag and Roland Barthes, she seeks to understand, and refine, the philosophical norms that inform this distinction. Unlike text-based invasions, photographs capture something more than just information; they capture the 'chief attributes' of personality. In the most problematic cases, photographs present the subject at their most vulnerable for public scrutiny and critique. Revealing the individual's emotional state, though, overrides that person's autonomy. Whereas emotions are revealed naturally, those moments are transitory. The image that the witness gains, therefore, is one of many by which to make rounded judgements of the individual's personality (and flaws). A picture, however, provides both a partial and permanent expression of one aspect of personality. Consequently, the momentary emotional state is inflated and leads (or can lead) to a 
distorted image of that person. As Moosavian concludes, it is both this capacity to capture vulnerability and to so intensely misrepresent its significance to personality that explains (or helps explain) the unique emotional distress that candid photographs cause.

As these articles demonstrate, the issues raised by The Circle are numerous and multidisciplinary. Clearly, there is a profound change happening in our social and cultural expectations of privacy, data protection and democratic discourse which the law is yet to properly comprehend, let alone address. In this way, the articles contribute to an important dialogue that is already underway. They set out their own contribution to the agenda, by staking out the serious threat to autonomy that is taking place. Reasonable people will disagree over what needs to be done, and certainly there are no easy answers, but perhaps we should be guided by the insight one character in The Circle provides: 'We are not meant to know everything, Mae.' 
